\title{
Intrathecal Triiodothyronine Administration Causes Greater Heart Rate Stimulation in Hypothyroid Rats than Intravenously Delivered Hormone Evidence for a Central Nervous System Site of Thyroid Hormone Action
}

\author{
Morris Goldman, Mary B. Dratman, Floy L. Crutchfield, Anthony S. Jennings, Joel A. Maruniak, and Robert Gibbons \\ Department of Psychiatry, University of Chicago, Chicago, Illinois 60637; Philadelphia Veterans Administration Medical Center, and \\ Department of Medicine, Medical College of Pennsylvania, Philadelphia, Pennsylvania 19104; Department of Medicine, School of \\ Medicine; and Department of Physiology, University of Pennsylvania, Philadelphia, Pennsylvania 19104; and Department of Psychiatry \\ and Biometry, University of Illinois, Chicago, Illinois 60612
}

\begin{abstract}
To determine whether intracerebrally localized iodothyronines produce thyroid hormone-related functional effects, heart rate responses were compared in conscious hypothyroid rats given triiodothyronine $\left(\mathrm{T}_{3}\right)$ by either the intrathecal or the intravenous route. A significant increase in heart rate occurred within $18 \mathrm{~h}$ after $1.5 \mathrm{nmol} \mathrm{T}_{3} / 100 \mathrm{~g}$ body wt was delivered intrathecally through a cannula previously placed in the lateral cerebral ventricle. Injection of the same $T_{3}$ dose intravenously through an indwelling jugular catheter or injection of vehicle only by either route produced no significant increase in heart rate during the 48-h postinjection period of observation. These differences were observed even though integrated serum $T_{3}$ concentrations were significantly lower after intrathecal than after intravenous $T_{3}$ injection. The results indicate that thyroid hormone effects on heart rate are exerted within the brain as well as within the heart.
\end{abstract}

\section{Introduction}

Recent observations have demonstrated that brain iodothyronines are under strong homeostatic control (1), cross the bloodbrain barrier through a high-affinity transport mechanism (2), are actively metabolized $(3,4)$ and processed in discrete neural pathways $(5)$, are concentrated in synaptosomes $(3,6)$, and bind with high affinity to a limited number of sites in nerve cell nuclei (7) and synaptosomes (8). Thus far, however, only indirect evidence suggests that intracerebrally localized thyroid hormones produce changes in neural structure (9) or function (10).

To test for a causal relationship between brain iodothyronines and nervous system activity, we measured the effect of a single injection of triiodothyronine $\left(\mathrm{T}_{3}\right)^{1}$ or vehicle given intrathecally on an adrenergically responsive process, heart rate, in conscious hypothyroid rats. Although the amount of $\mathrm{T}_{3}$ given $(1.5 \mathrm{nmol} /$ $100 \mathrm{~g}$ body $\mathrm{wt}$ ) was considerably less than that previously reported to cause an increase in heart rate when given systemically

Address reprint requests to Dr. Goldman, Department of Psychiatry, University of Chicago Medical Center, 5841 South Maryland, Chicago, IL 60637.

Received for publication 26 March 1985.

1. Abbreviations used in this paper: bpm, beats per minute; df, degrees of freedom; $\mathrm{rT}_{3}$, reverse triiodothyronine; $T_{3}$, triiodothyronine; $T_{4}$, thyroxine.

J. Clin. Invest.

(c) The American Society for Clinical Investigation, Inc.

0021-9738/85/10/1622/04 \$1.00

Volume 76, October 1985, 1622-1625 as a single injection (11), intrathecal administration of this dose was followed within $18 \mathrm{~h}$ by a significant increase in heart rate. Under șimilar conditions, no increase in heart rate was observed in rats given thyroxine $\left(\mathrm{T}_{4}\right)$ or reverse triiodothyronine $\left(\mathrm{rT}_{3}\right)$ intrathecally. Moreover, when heart rate response to intrathecal $T_{3}$ was compared with the response after intravenous $T_{3}$ or vehicle given by either route, a significant increase in heart rate was noted only in animals given $T_{3}$ intrathecally.

\section{Methods}

Surgically thyroidectomized rats received from Zivic-Miller Laboratories (Allison Park, PA) were given free access to Purina chow (Ralston Purina Co., St. Louis, $\mathrm{MO}$ ) and $0.5 \% \mathrm{CaCl}_{2}$ as drinking water. All rats showed the expected plateau in body weight gain; the duration of hypothyroidism was 3-6 wk in the first and second experiments and 2-4 wk in the third and fourth experiments. Rats used in any one experiment were of similar age, were thyroidectomized on the same day, and were housed in a laboratory space dedicated exclusively to the experiment. All animal care was administered and all treatments were carried out by a single investigator.

Experiment no. 1. Rats were paired by body weight (range, 200-250 g) and were handled as pairs throughout. Rats were anaesthesized with intraperitoneal nembutal $(40 \mathrm{mg} / \mathrm{kg})$ and atropine $(0.1 \mathrm{mg} / \mathrm{kg})$, and a 23-gauge cannula was lowered through a burr hole in the left lateral cerebral ventricle (coordinates: $0.6 \mathrm{~mm}$ posterior to bregma, $1.5 \mathrm{~mm}$ lateral to saggital sinus, $3.0 \mathrm{~mm}$ below dura), using stereotactic guidance (12). A small incision was made over the precordial area and a fine teflon-coated Medwire ( $50 \mu \mathrm{M}$; Medwire Corp., Mt. Vernon, NY), bared at its end, was sutured to the subcutaneous fat and passed subcutaneously until exteriorized at the nape of the neck; a second length of Medwire was placed subcutaneously over the cranium to act as a reference electrode. The free ends of both wires were placed in a male microconnector strip $(2 \times 5 \times 10 \mathrm{~mm})$ and secured along with the intraventricular cannula to the skull with self-tapping screws and Craniofacial Cement (Plastic Products, Roanoke, VA). $2 \mathrm{~d}$ later, when the rats were fully recovered, the monitoring leads were connected via a female microconnector strip and flexible protected cable to a preamplifier and recorder wired to an electronic timer; this was arranged as to allow the animals to move about freely in their cages. Heart rate was recorded simultaneously every 30 min in each member of the pair. After $18 \mathrm{~h}$ of recording to allow adaptation to the equipment and obtain base-line values, one rat of each pair was given $1.5 \mathrm{nmol} \mathrm{T}_{3} / 100 \mathrm{~g}$ body wt in $4 \mu \mathrm{l}$ of $0.2 \mathrm{~N} \mathrm{NaOH}$, which was delivered through the cannula over $120 \mathrm{~s}$, while the other rat of the pair received $4 \mu \mathrm{l}$ of $0.2 \mathrm{~N} \mathrm{NaOH}$. The interval between injections rarely exceeded $15 \mathrm{~min}$; injections were made in the afternoon, generally between 2 and 5 p.m. Recordings were continued for $48 \mathrm{~h}$ after intrathecal $\mathrm{T}_{3}$ or $\mathrm{NaOH}$ administration. Data recorded during the 12 -h period before injection were averaged to calculate base-line values; the overall level of heart rate response was derived from values averaged over the 48 -h postinjection period of observation. Four successive mean counts were averaged to obtain a mean heart rate for each 2-h postinjection period; corresponding values obtained from vehicle-treated $(n=5)$ or $\mathrm{T}_{3}$-treated $(n=5)$ rats were then averaged to obtain an overall mean 2 -h value $\pm S D$. 
Experiment no. 2. To control for the possibility of a nonspecific effect of intrathecally administered iodothyronine, rats prepared and monitored as described in the first experiment were given $1.5 \mathrm{nmol} / 100 \mathrm{~g}$ body wt of $\mathrm{T}_{4}(n=4), \mathrm{rT}_{3}(n=5)$, or $\mathrm{NaOH}(n=4)$ intrathecally.

Experiment no. 3. To compare the heart rate-modifying effect of intravenous $T_{3}$ with that of intracerebral $T_{3}$, silicone jugular venous catheters $(0.037 \mathrm{~cm}$ o.d., Silastic; Dow Corning Corp., Midland, MI) were implanted in hypothyroid rats (150-200 $\mathrm{g}$ body wt) otherwise prepared and monitored as described in the first experiment. Pairs of rats were given $1.5 \mathrm{nmol} \mathrm{T}_{3} / 100 \mathrm{~g}$ body wt or $\mathrm{NaOH}$ by intravenous or intrathecal injection (see experiment 4 for intravenous injection volumes) and were observed simultaneously ( $n=6$ in each category).

Experiment no. 4. To compare changes in serum $T_{3}$ concentrations after intrathecal and intravenous administration, matched pairs of hypothyroid rats averaging $260 \mathrm{~g}$ body wt had the required cannulas implanted under anaesthesia; $2 \mathrm{~d}$ later, seven rats received $3.9 \mathrm{nmol} \mathrm{T}_{3}$ in $4.0 \mu \mathrm{l}$ of $2 \mathrm{~N} \mathrm{NaOH}$ intrathecally and four rats received the same amount of intravenous $\mathrm{T}_{3}$ given in $130 \mu \mathrm{l}$ of $6 \times 10^{-4} \mathrm{NaOH}$ through the indwelling silicone tubing and followed by $1 \mathrm{ml}$ of saline. Experiments with ${ }^{125} \mathrm{I}-\mathrm{T}_{3}$ revealed no adsorption of $\mathrm{T}_{3}$ to the tubing. $1 \mathrm{ml}$ of blood for $T_{3}$ measurement was withdrawn and replaced by an equal volume of saline immediately before $\mathrm{T}_{3}$ administration, and again at $5 \mathrm{~min}$ (preceded by $0.02 \mathrm{ml}$ blood withdrawn and discarded at that interval only) and the other time intervals shown on the abscissa in Fig. 4. Serum was separated in a refrigerated centrifuge and $T_{3}$ was measured by radioimmunoassay (13). All determinations were made in a single assay; the intraassay coefficient of variation was $\sim 5 \%$.

Data analysis. To avoid overestimation of significant differences in analyzing sequential heart rate changes, the method of multivariate analysis of variance for repeated measures was chosen. This method allows correlations between time points without assuming independence between points or equal correlations over time (14). It compares treatment groups in terms of both the overall level of heart rate (constant term) and the shape of the time trends. The shape of the time trends are modeled on a third degree orthogonal polynomial, thus allowing comparisons of the linear rate of change ( $x$ term) and the pattern of response $\left(x^{2}\right.$ and $x^{3}$ terms) between groups. All data are expressed as the mean \pm SD.

\section{Results}

Effect of intrathecal $T_{3}$ (Fig. 1). All rats received either $T_{3}$ or vehicle intrathecally. The heart rate did not change in response to vehicle (base-line heart rate: $332 \pm 29$ beats per minute (bpm) after intrathecal $\mathrm{NaOH}: 331 \pm 21 \mathrm{bpm}$ ). In $\mathrm{T}_{3}$-treated rats, the heart rate increased significantly from $326 \pm 24 \mathrm{bpm}$ before to $343 \pm 25 \mathrm{bpm}$ after intrathecal administration $(P<0.02)$. Comparison of results in $\mathrm{T}_{3}$-treated vs. vehicle-treated animals revealed significant differences in both the overall heart rate level $(F=8.5$, degrees of freedom $(\mathrm{df})=1,8 ; P<0.02)$ and the rate of heart rate change over time $(F=5.0$, df $=1,8 ; P<0.05)$. The results indicate that $T_{3}$ enhanced heart rate overall and that this occurred in a linearly increasing fashion. This is apart from the diurnal pattern of heart rate response which is apparent and similar in both groups.

Effect of other iodothyronines (Fig. 2). To exclude the possibility that the results after intrathecal $T_{3}$ were due to nonspecific heart rate-stimulating effects of intrathecally administered iodothyronine, a three-way comparison of heart rates was carried out after administration of $1.5 \mathrm{nmol} / 100 \mathrm{~g}$ body wt of either $\mathrm{T}_{4}, \mathrm{rT}_{3}$, or $\mathrm{NaOH}$. The heart rate did not change significantly in any group and pre- and postinjection values were not significantly different among groups (pre- and postinjection values, respectively: $T_{4}, 329 \pm 27$ and $339 \pm 22 \mathrm{bpm} ; \mathrm{rT}_{3}, 308 \pm 21$ and $301 \pm 30 \mathrm{bpm} ; \mathrm{NaOH}, 322 \pm 29$ and $327 \pm 16 \mathrm{bpm}$ ).

Effect of intravenous $T_{3}$ (Fig. 3). Additional experiments were

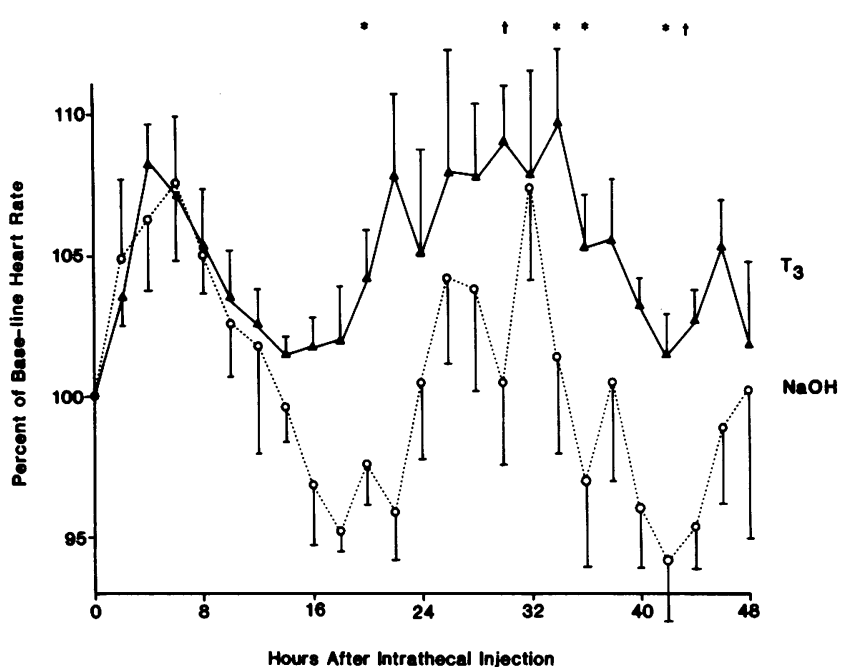

Figure 1. Fractional heart rate changes after intrathecal administration of $T_{3}$ or vehicle. Hypothyroid rats were prepared and monitored as described in Methods. Mean heart rates for each $2-h$ postinjection period is expressed as a fraction of the mean base-line heart rate $\pm \mathrm{SD}$. The overall difference between vehicle-treated and $T_{3}$-treated rats was significant $(P<0.02) ; t$ test at each time interval showed significant differences as indicated by ${ }^{*}(P<0.05)$ or $\dagger(P<0.02) ; n=5$.

conducted to confirm the intrathecal $T_{3}$ effect and to determine the heart rate response in intravenous $T_{3}$-treated animals when handled and evaluated by the methods used in these investigations. A four-way comparison of heart rate was carried out after administration of $\mathrm{T}_{3}$ or vehicle by the intrathecal or intravenous route. A diurnal variation in heart rate response was not observed in any of four groups of rats studied in this experiment, although it was observed in the groups studied in the first and second experiments (see Figs. 1 and 2). The reason for this difference is unclear.

Base-line and posttreatment heart rates, respectively, were: $372 \pm 26$ and $369 \pm 34 \mathrm{bpm}$, intrathecal $\mathrm{NaOH} ; 370 \pm 34$ and $394 \pm 27 \mathrm{bpm}$, intrathecal $\mathrm{T}_{3} ; 382 \pm 34$ and $358 \pm 43 \mathrm{bpm}$, intravenous $\mathrm{NaOH} ; 380 \pm 24$ and $379 \pm 25 \mathrm{bpm}$, intravenous $\mathrm{T}_{3}$. Multivariate analysis of variance for repeated measures showed an overall increase over base-line heart rates only in rats given

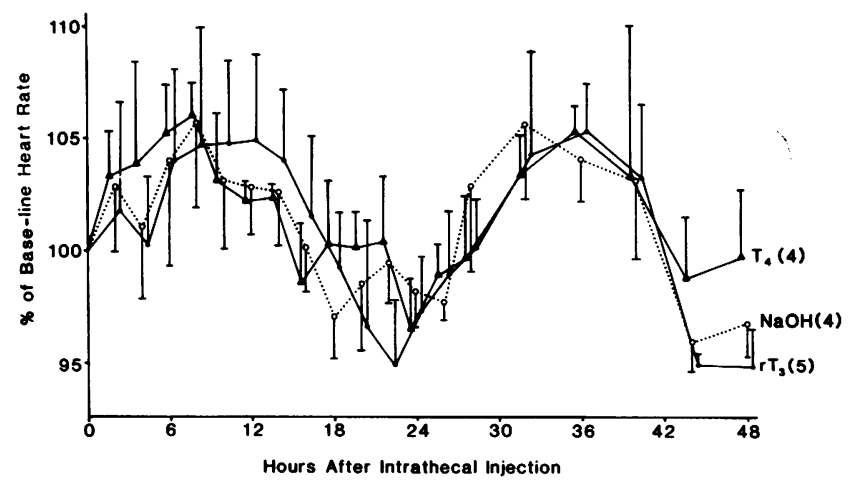

Figure 2. Mean fractional heart rate changes \pm SD after intrathecal administration of $1.5 \mathrm{nmol} \mathrm{T}_{4}$ or $\mathrm{rT}_{3} / 100 \mathrm{~g}$ body wt or vehicle to rats prepared and monitored as described in experiment 1 . No significant heart rate change over base line was noted in any group; overall differences in postinjection heart rates among rats given $\mathrm{T}_{4}, \mathrm{rT}_{3}$, or $\mathrm{NaOH}$ were not significant. $\cdots \circ \cdots, \mathrm{NaOH} ;-\bullet-, \mathrm{rT}_{3} ; \Delta, \mathrm{T}_{4}$. 


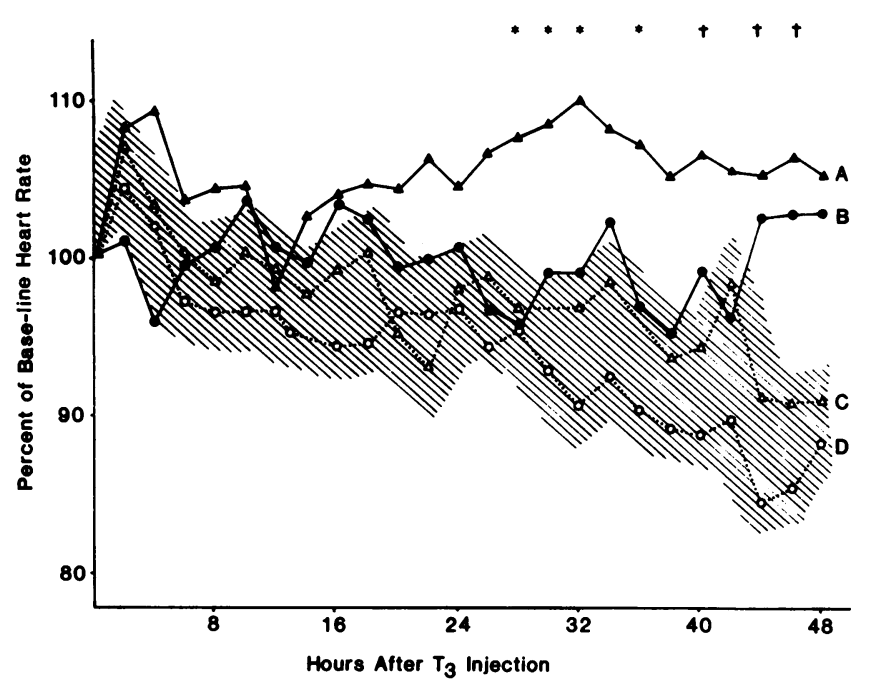

Figure 3. Effect of route of administration on fractional heart rate response to $\mathrm{T}_{3}$. Pairs of rats receiving $1 \mu \mathrm{g} \mathrm{T} / 100 \mathrm{~g}$ body wt or $\mathrm{NaOH}$ by intravenous or intrathecal injection were observed simultaneously. Mean fractional changes from base line are shown in two hourly intervals after intrathecal $T_{3}(A,-\Delta-)$, intravenous $T_{3}(B,-\bullet-)$, intrathecal $\mathrm{NaOH}(\mathrm{C}, \cdots \Delta \cdots)$, or intravenous $\mathrm{NaOH}(\mathrm{D}, \cdots 0 \cdots)$; shaded area shows composite range of SD for $\mathrm{NaOH}$-treated groups which were not significantly different from each other. Fractional heart rate responses in intrathecally $T_{3}$-treated rats were significantly greater than in those given intravenous $\mathrm{T}_{3}(P<0.04)$ or in $\mathrm{NaOH}$ treated groups separately or combined $(P<0.02)$; $t$ test revealed significantly increased rates after intrathecal $\mathrm{T}_{3}$ relative to intrathecal $\mathrm{NaOH}$ at time intervals shown by ${ }^{*}(P<0.05)$ or $\dagger(P<0.02) ; n=6$ in each category.

intrathecal $T_{3}$; these increases were established by $18 \mathrm{~h}$ after injection and were significant whether compared with rates after intrathecal $\mathrm{NaOH}(F=8.3, \mathrm{df}=4,10 ; P<0.01)$ or intravenous $\mathrm{T}_{3}(F=5.3$, df $=4,10 ; P<0.04)$. No significant heart rate change was found in the rats given $\mathrm{NaOH}$ and no significant differences were noted between rats receiving $\mathrm{NaOH}$ by the intravenous vs. the intrathecal route $(P<0.24)$. Though overall heart rate responses of rats given intravenous $T_{3}$ were not significantly different from those given intravenous $\mathrm{NaOH}(P$ $<0.13$ ), the possibility that a delayed effect of intravenous $T_{3}$ would have appeared if the experiment had been prolonged beyond $48 \mathrm{~h}$ was suggested by a linear trend toward increased heart rate which approached significance $(P<0.08)$.

Serum $T_{3}$ levels after intravenous and intrathecal $T_{3}$ administration (Fig. 4). To determine the rapidity and extent that intrathecally administered $T_{3}$ appears in the bloodstream, we compared serum $T_{3}$ levels (radioimmunoassay) in a separate group of matched hypothyroid rats given $T_{3}$ by the intravenous or intrathecal route. Time-integrated serum $\mathrm{T}_{3}$ values were significantly higher in the intravenous-treated animals $(P<0.01)$. Therefore, the heart and other peripheral tissues were exposed to significantly higher serum concentrations of $T_{3}$ after intravenous than after intrathecal $\mathrm{T}_{3}$ administration.

\section{Discussion}

Thyroid hormones pass from blood to brain by a carrier-mediated mechanism with affinity for $T_{3}$ which is reported to exceed that of any known hormone transport system operating across

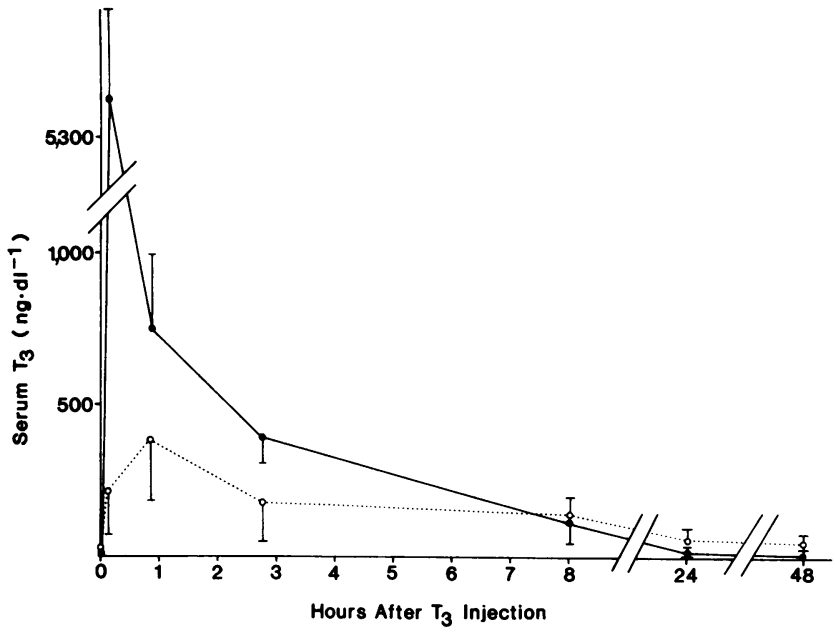

Figure 4. Serum $T_{3}$ concentrations following intravenous or intrathecal $T_{3}$ administration. Base-line $T_{3}$ values of the two groups were in the hypothyroid range and were not significantly different from each other. Differences between the groups were significant at 5, 50, and 150 min but not thereafter; at 24 and $48 \mathrm{~h}$, serum $\mathrm{T}_{3}$ levels had returned to base line in the intravenous $T_{3}$-injected group but were still significantly above base line in the intrathecally $\mathrm{T}_{3}$-injected animals. Integrated $\mathrm{T}_{3}$ values were significantly higher by $40 \%$ in rats receiving the hormone intravenously $(P<0.01)$ as compared with rats treated by the intrathecal route.

the blood-brain barrier (2). However, the capacity of this system is small, and as a result, $T_{3}$ in the systemic circulation equilibrates very slowly with brain, with a half-time between 3 and $6 \mathrm{~h}$ (3). Therefore, centrally mediated effects of $T_{3}$ reaching the brain through the systemic circulation are likely to be delayed as compared with $\mathrm{T}_{3}$ effects in peripheral tissues. We have observed that $T_{3}$ administration by the intrathecal route results in a faster rate of uptake and a greater concentration of hormone within the brain as compared with results after intravenous administration (data not shown). While intrathecal injection does not guarantee more efficient or rapid delivery to any particular brain region, circumventing the blood-brain barrier by using the intrathecal route has proven to be useful in promoting brain uptake of many compounds (15).

The $T_{3}$ dose used in these experiments $(1,000 \mathrm{ng} / 100 \mathrm{~g})$ is higher than considered physiologic (serum $T_{3}$ production rate in the rat is $\sim 200-250 \mathrm{ng} / 100 \mathrm{~g}$ per d). However, functional responses of hypothyroid subjects to a physiologic thyroid hormone dose usually follows repeated administration of that amount. When the response to a single dose of $T_{3}$ is being evaluated, it is usual to give a dose at an order of magnitude greater than we gave in these experiments (for examples, see references 11,16 , and 17). Evidence that we chose an appropriate dose for these investigations is indicated by the responses themselves. A sensitive indicator of $\mathrm{T}_{3}$ effects, heart rate, did not change significantly when $1.5 \mathrm{nM} \mathrm{T}_{3}$ was given intravenously, whereas a small but significant heart rate change was caused by intrathecal injection of the same amount. It would have been interesting to observe the response to even larger amounts of $T_{3}$, but the dose was limited by the solubility of the hormones and the requirement to inject no more than a $4-\mu l$ volume into the lateral cerebral ventricle.

Two previous reports have shown that a significant increase in core temperature occurs following intrathecal $\mathrm{T}_{4}$ administra- 
tion $(18,19)$. While the evidence is compatible with a central nervous system mechanism of $\mathrm{T}_{4}$ action, the experiments were not controlled so as to examine this point specifically. We chose to study effects of central nervous system iodothyronines on heart rate because this function is $(a)$ dependent not only on peripheral mechanisms but also on mechanisms integrated and controlled in the brain (20); (b) markedly susceptible to changes in thyroid hormone availability $(21) ;(c)$ stimulated by thyroid hormones at least in part through a nervous system-related mechanism (22); and $(d)$ susceptible to quantitative measurements. Under the conditions of these experiments, no heart rate change was observed after intrathecal $\mathrm{T}_{4}$ or $\mathrm{rT}_{3}$, indicating that the response measured was specific to $T_{3}$. We ascribe the greater (or earlier) heart rate change observed after intrathecal as compared with intravenous $T_{3}$ to its earlier uptake and higher concentration in $\mathrm{T}_{3}$-responsive centers in brain.

While the data reported here point to a $T_{3}$-responsive central nervous system mechanism in heart rate regulation, the results in no way detract from the heart rate-stimulating effects of $T_{3}$ exerted within the neural or myocardial components of the heart itself. Rather, bidirectional passage of iodothyronines across the blood-brain barrier (23) would make it likely that both central and peripheral iodothyronine-dependent processes are involved in regulating cardiovascular dynamics. Though the cellular mechanism is still unknown, the information provided by this study adds to existing biochemical and autoradiographic evidence $(3,5,6)$ supporting a neuroregulatory role for $T_{3}$ or its metabolites within the central nervous system.

\section{Acknowledgments}

We thank E. Erlichman for editorial assistance.

This work was supported by the Veterans Administration Medical Research Service, National Science Foundation grant BNS82-10354, and 2 R01 AM-30532-04.

\section{References}

1. Dratman, M. B., F. L. Crutchfield, J. T. Gordon, and A. S. Jennings. 1983. Iodothyronine homeostasis in rat brain during hypo- and hyperthyroidism. Am. J. Physiol. 245:E185-E193.

2. Pardridge, W. M. 1979. Carrier-mediated transport of thyroid hormones through the rat blood-brain barrier: primary role of albuminbound hormone. Endocrinology. 105:605-612.

3. Dratman, M. B., and F. L. Crutchfield. 1978. Synaptosomal $\left[{ }^{125} \mathrm{I}\right]$ triiodothyronine following intravenous $\left[{ }^{125} \mathrm{I}\right]$ thyroxine. Am. J. Physiol. 4:E638-647.

4. Kaplan, M. M., and K. A. Yaskoski. 1980. Phenolic and tyrosyl ring deiodination of iodothyronines in rat brain homogenates. J. Clin. Invest. 66:551-562.

5. Dratman, M. B., Y. Futaesaku, F. L. Crutchfield, N. Berman, B. Payne, M. Sar, and W. E. Stumpf. 1982. Iodine 125-labelled triiodothyronine in rat brain: evidence for localization in discrete neural systems. Science (Wash. DC). 215:309-312.
6. Dratman, M. B., F. L. Crutchfield, J. Axelrod, R. W. Colburn, and N. Thoa. 1976. Localization of triiodothyronine in nerve ending fractions of rat brain. Proc. Nat. Acad. Sci. USA. 73:941-944.

7. Schwartz, H. L., and J. H. Oppenheimer. 1978. Nuclear triiodothyronine receptor sites in brain: probable identity with hepatic receptors and regional distribution. Endocrinology. 103:267-273.

8. Mashio, Y., M. Inada, K. Tanaka, H. Ishii, K. Naitro, M. Nishikowa, K. Takahashi, and H. Imura. 1982. High affinity 3,5,3'-L-triiodothyronine binding to synaptosomes in rat cerebral cortex. Endocrinology. 110:1257-1261.

9. Riuz-Marcos, A., F. Salas, F. Sanchez-Toscano, F. Escobar del Rey, and G. Morreale de Escobar. 1983. Effect of neonatal and adultonset hypothyroidism on pyramidal cells of the rat auditory cortex. Dev. Brain Res. 9:205-213.

10. Emlen, W., D. S. Segal, and A. J. Mandell. 1972. Thyroid state: effects on pre- and postsynaptic central noradrenergic mechanism. Science (Wash. DC). 175:79-82.

11. Bray, G., and H. M. Goodman. 1965. Studies on the early effects of thyroid hormones. Endocrinology. 76:323-328.

12. Meselis, R. R., and A. N. Epstein. 1975. Feeding induced by intracerebroventricular 2-deoxy-D-glucose in the rat. Am. J. Physiol. 229: 1438-1444.

13. Jennings, A. S., D. C. Ferguson, and R. D. Utiger. 1979. Regulation of the conversion of thyroxine to triiodothyronine in the perfused rat liver. J. Clin. Invest. 64:1614-1623.

14. Bock, R. D. 1975. Multivariate Statistical Methods in Behavioral Research. McGraw Hill, New York. 449-489.

15. Myers, R. D. 1974. Handbook of Drug and Chemical Stimulation of Brain. Behavioral, Pharmacological, and Physiological Aspects. Van Nostrand Reinhold Co., New York.

16. Leonard, J. L., M. M. Kaplan, T. J. Visser, J. E. Silva, and P. R. Larsen. 1981. Cerebral cortex responds rapidly to thyroid hormone. Science (Wash. DC). 214:571-573.

17. DeGroot, L. J., P. Rue, M. Robertson, J. Bernal, and N. Scherberg. 1977. Triiodothyronine stimulates nuclear RNA synthesis. Endocrinology. 101:1690-1700.

18. Belesin, D. B., and R. Samardzic. 1973. Effect of thyroxine on the body temperature after its intraventricular injection into conscious cats. J. Physiol. 238:27P-28P.

19. Kaciuba-Uscilko, H., J. Sobocinski, S. Kozlowski, and A. W. Ziemba. 1976. Effect of intraventricular thyroxine administration on body temperature in dogs at rest and during physical exercise. Experientia (Basel). 32:351-352.

20. Korner, P. I. 1971. Integrative neural cardiovascular control. Physiol. Rev. 51:312-367.

21. Pietros, R. J., M. A. Real, G. S. Poticha, D. Bronsky, and S. Waldstein. 1972. Cardiovascular response in hyperthyroidism. Arch. Intern. Med. 129:426-429.

22. Dratman, M. B. 1978. The mechanism of thyroxine action. In Hormonal Proteins and Peptides. C. H. Li, editor. Academic Press, New York. 238-257.

23. Chernow, B., K. D. Burman, D. L. Johnson, R. A. McGuire, J. T. O'Brien, L. Wartofsky, and L. P. Georges. 1983. T 3 may be a better agent than $\mathrm{T}_{4}$ in the critically ill hypothyroid patient: evaluation of transport across the blood-brain barrier in a primate model. Critical Care Med. 11:99-104. 